\title{
Emergency department and hospital admissions among people with dementia living at home or in nursing homes: results of the European RightTimePlaceCare project on their frequency, associated factors and costs
}

F. Javier Afonso-Argilés ${ }^{1,2}$, Gabriele Meyer ${ }^{3,4^{*}}$, Astrid Stephan ${ }^{3,4}$, Mercè Comas ${ }^{5,6}$, Ansgar Wübker ${ }^{7}$, Helena Leino-Kilpi ${ }^{8}$, Connie Lethin ${ }^{9,10}$, Kai Saks ${ }^{11}$, Maria Soto-Martin ${ }^{12}$, Caroline Sutcliffe ${ }^{13}$, Hilde Verbeek ${ }^{14,15}$, Adelaida Zabalegui 16,17, Anna Renom-Guiteras ${ }^{2,6,18}$ and on behalf of the RightTimePlaceCare Consortium

\begin{abstract}
Background: Evidence is lacking on the differences between hospitalisation of people with dementia living in nursing homes and those living in the community. The objectives of this study were: 1 ) to describe the frequency of hospital admission among people with dementia in eight European countries living in nursing homes or in the community, 2) to examine the factors associated with hospitalisation in each setting, and 3) to evaluate the costs associated with it.

Methods: The present study is a secondary data analysis of the RightTimePlaceCare European project. A crosssectional survey was conducted with data collected from people with dementia living at home or who had been admitted to a nursing home in the last 3 months, as well as from their caregivers. Data on hospital admissions at 3 months, cognitive and functional status, neuropsychiatric symptoms, comorbidity, polypharmacy, caregiver burden, nutritional status, and falls were assessed using validated instruments. Multivariate regression models were used to investigate the factors associated with hospital admission for each setting. Costs were estimated by multiplying quantities of resources used with the unit cost of each resource and inflated to the year 2019.

(Continued on next page)
\end{abstract}

\footnotetext{
* Correspondence: gabriele.meyer@medizin.uni-halle.de

${ }^{3}$ Department of Nursing Science, Witten/Herdecke University, Witten, Germany

${ }^{4}$ Institute of Health and Nursing Sciences, Medical Faculty, Martin Luther University Halle-Wittenberg, Halle (Saale), Germany

Full list of author information is available at the end of the article
}

(c) The Author(s). 2020 Open Access This article is licensed under a Creative Commons Attribution 4.0 International License, which permits use, sharing, adaptation, distribution and reproduction in any medium or format, as long as you give appropriate credit to the original author(s) and the source, provide a link to the Creative Commons licence, and indicate if changes were made. The images or other third party material in this article are included in the article's Creative Commons licence, unless indicated otherwise in a credit line to the material. If material is not included in the article's Creative Commons licence and your intended use is not permitted by statutory regulation or exceeds the permitted use, you will need to obtain permission directly from the copyright holder. To view a copy of this licence, visit http://creativecommons.org/licenses/by/4.0/ The Creative Commons Public Domain Dedication waiver (http://creativecommons.org/publicdomain/zero/1.0/) applies to the data made available in this article, unless otherwise stated in a credit line to the data. 
(Continued from previous page)

Results: The study sample comprised 1700 people with dementia living in the community and nursing homes. Within 3 months, 13.8 and $18.5 \%$ of people living in nursing homes and home care, respectively, experienced $\geq 1$ hospital admission. In the nursing home setting, only polypharmacy was associated with a higher chance of hospital admission, while in the home care setting, unintentional weight loss, polypharmacy, falls, and more severe caregiver burden were associated with hospital admission. Overall, the estimated average costs per person with dementia/year among participants living in a nursing home were lower than those receiving home care.

Conclusion: Admission to hospital is frequent among people with dementia, especially among those living in the community, and seems to impose a remarkable economic burden. The identification and establishment of an individualised care plan for those people with dementia with polypharmacy in nursing homes, and those with involuntary weight loss, accidental falls, polypharmacy and higher caregiver burden in the home care setting, might help preventing unnecessary hospital admissions.

Keywords: Aged, Dementia, Geriatric syndrome, Home care, Hospitalisation, Nursing home

\section{Background}

Dementia is a major cause of disability and dependency among older people worldwide and has a psychological, social and economic impact on the persons affected, their families and caregivers, and the society [1]. People with dementia have increasing needs for care and supervision throughout the course of their disease, usually leading to the need for support from relatives or other informal caregivers and, when the needs of people with dementia are increased, many of them need to receive care in nursing homes $(\mathrm{NH})$ [2].

Admission to hospital due to acute medical problems, including the admission to the emergency departments, is one of the events that people with dementia may experience throughout the course of the disease, irrespectively of whether they live at their own home or at $\mathrm{NH}$. Despite the benefits of receiving specialized care, multiple negative health outcomes have been associated with the admission to hospital of older people in general and people with dementia in particular, including high risk of delirium [3], functional decline [4], fall-related injuries [5], nosocomial infections, pressure ulcers [6], and an elevated risk of mortality $[7,8]$.

In a recent systematic review of the literature, Shepherd et al. (2019) concluded that people with dementia are more frequently admitted to hospital than those without dementia, and identified hospitalisation rates in people with dementia between 0.37 and 1.26 /person-year in high-quality studies [9]. However, studies on people with dementia that predominantly resided in long-term nursing care facilities were excluded from this review. Maxwell et al. (2015) reported an annual hospitalisation rate of 0.10 per person-year among people with dementia living in $\mathrm{NH}[10]$.

In their meta-analysis, Shepherd et al. (2019) found strong evidence that multimorbidity, polypharmacy, and lower functional ability are associated with hospital admission, and strong evidence that dementia severity alone is not associated [9]. However, there is a lack of studies reporting on factors associated with hospitalisation among people with dementia living in $\mathrm{NH}$.

Geriatric syndromes are known to predict an increased likelihood of hospitalisation, affect quality of life [11], increase the use and cost of health care, and raise overall mortality among the general older population [12, 13]. However, relevant geriatric syndromes such as malnutrition or falls have not been evaluated as potential factors associated with hospital admissions in the studies involving people with dementia [9]. Furthermore, even if caregivers of people with dementia have a crucial role in the care and resource use in this population, only few studies have analyzed the effects that their psychological wellbeing may have on the decisions of hospital admission of these people [14].

Even if the economic cost of dementia has been widely evaluated in recent years [15], only few studies have provided a detailed description of the costs of hospital admission among people with dementia taking their living situations into consideration [16]. This information may be helpful for the planning of the provisions of care.

Thus, there is a lack of studies that describe and compare the frequency of hospital admission in both the community and $\mathrm{NH}$ settings, investigate and compare the factors associated with hospital admission in both settings, and provide information on its costs.

\section{Aim}

The aims of the present study were: 1) to describe the frequency of hospital admissions (including Emergency Department), among people with dementia from eight European countries living in the community and those living in nursing homes; 2) to examine the factors associated with hospital admissions among people with dementia living in the community and those living in nursing homes settings, separately; 3 ) to evaluate the 
costs associated with hospital admissions according to the different living situations.

\section{Methods \\ Design}

This study is a secondary analysis of a large European research project called 'RightTimePlaceCare' (RTPC). The RTPC survey was a longitudinal prospective study, conducted in eight European countries (Estonia, Finland, France, Germany, Netherlands, Spain, Sweden, and the United Kingdom). The project aimed to improve health and social care services for European citizens with dementia and focused on the transition from professional home care towards institutional nursing care. Further details are published elsewhere [17].

\section{Participants}

The RTPC survey comprised two groups of participants: 1) People with dementia newly admitted to $\mathrm{NH}$ (i.e. within one to 3 months after admission) and their informal caregivers; 2) People with dementia who received professional home care and were at risk of institutionalization (as judged by a professional responsible for their care) along with their informal caregivers. Informal caregivers could include spouses/partners, other family members, relatives, friends, neighbours or other unpaid individuals within their social network [18]. The number of informal caregivers was limited to one main informal caregiver per person with dementia, defined as the person who was most involved in care for the people with dementia. For people living in $\mathrm{NH}$, the next of kin or significant other was included, being the person closest to the person with dementia (spouse, children, grandchildren, other relatives, or friends) and who was most involved in decisions about their care.

Inclusion criteria for people with dementia were if they (1) had a primary diagnosis of dementia as diagnosed by an expert (e.g. physician, psychiatrist, neurologist, geriatrician, or general practitioner, depending on countries' diagnostic procedures) and recorded in the medical records; (2) scored 24 points or lower on the Standardized Mini Mental State Examination (S-MMSE) [19]; and (3) had an informal caregiver who visited the people with dementia at least twice a month. People with dementia were excluded when they (1) were younger than 65 years; (2) had a primary psychiatric diagnosis or Korsakoff syndrome; and, for the group recently admitted to $\mathrm{NH},(3)$ were only temporarily resident in the $\mathrm{NH}$ (e.g. rehabilitation, respite of the informal caregiver) with the intention of moving back home.

\section{Procedures}

Each country obtained ethical approval from a country specific legal authority for research on human beings (for example an ethical committee specialized in medical or nursing science) to conduct the study in accordance with their national standards and regulations. Countryspecific consent procedures were followed.

Data were collected by trained interviewers at baseline between November 2010 and April 2012 and follow-up interviews were conducted after 3 months [17]. All interviewers were professionals in health or social care or medical/nursing/social care students with practical experience and at least a Bachelor's degree.

\section{Measures \\ Sample characteristics}

At baseline, information on the age, sex, country and living situation (i.e. home care $(\mathrm{HC})$ vs nursing home $(\mathrm{NH})$ ) of the people with dementia was collected. Cognitive status was assessed with the S-MMSE (range 0-30), with higher scores indicating less cognitive impairment [19]. The disease severity was defined as mild (S-MMSE $>21$ ), moderate $(10-21)$, or severe $(<10)$ [20]. Participants who were unable to perform the S-MMSE due to cognitive or functional impairment were placed into the "severe dementia" group. Medical history of past and current clinical conditions were recorded based on the Charlson Comorbidity Index (CCI) (range 0-37), with higher scores indicating more clinical conditions and a score $>2$ indicating moderate comorbidity [21]. Independence in activities of daily living (ADL) was measured by the Katz index (range 0-6); we categorised dependency as mild (Katz index 5-6), moderate (2-4), or severe $(<2)$ [22]. Behavioural and psychiatric symptoms in dementia were evaluated with the Neuropsychiatric Inventory Questionnaire (NPI-Q). The NPI-Q comprises 12 domains (e.g. agitation and aggression, delusions, hallucinations) with 2 scores reported for each domain: (1) presence of symptoms and (2) severity on a $0-3$ scale $(0=$ none, $1=$ mild, $2=$ moderate, $3=$ severe; range $0-36$ ), with higher scores indicating more (severe) symptoms [23].

Furthermore, several quality of care indicators based on recent literature [24] were assessed at baseline: nutritional status (one item question 'did the person experience a weight loss of $4 \%$ or more of his/her weight in the past year?') [25, 26], polypharmacy ( $\geq 5$ drugs) [27] and the occurrence of falls during the preceding 3 months. Fall was defined as "an unexpected event in which the participant comes to rest on the ground, floor, or lower level" [28].

With regard to the informal caregivers, data on their age, sex and relationship with the person with dementia were collected. In addition, caregiver burden was measured using the Zarit Burden Interview (ZBI) [29]. Informal caregivers responded to 22 statements relating to the care of their relative with dementia using a Likert 
scale scoring system which ranged from "Never" to "Nearly Always". Total scores range from 0 to 88, with a higher score indicating higher perceived burden; three severity groups were defined: little or no burden $(\mathrm{ZBI}<21)$, mild burden ( $Z B I \geq 21-40$ ), or moderate to severe burden (ZBI > 40) [30].

In the $\mathrm{HC}$ setting, information on independence in $\mathrm{ADL}$, behavioural and psychiatric symptoms in dementia and quality of care indicators was asked to the informal caregivers of the people with dementia, while in the $\mathrm{NH}$ setting, this information was asked to the formal caregivers, as they were considered best informed proxies.

All measurement instruments were selected based on their psychometric properties (validity, reliability), clinical utility and appropriateness for the target settings and population [17].

\section{Information on emergency department and hospital admissions}

The Resource Utilization in Dementia (RUD) instrument was used to determine the health care resources used for people with dementia [31]. The RUD instrument captures medical care resources use (e.g. medication, inpatient and outpatient care), community care services (e.g. home care, transportation, meals on wheels, day care), special accommodation (e.g. nursing home) and time spent with caring activities by informal caregivers. Information on hospital visits since the baseline interview was gathered using an adapted version of the RUD instrument in the follow-up assessment that included the two concepts Hospital Admission (HA) and Emergency Department Admissions (EDA). In the HC setting, this information was asked to the informal caregivers, while in the $\mathrm{NH}$ setting, this information was asked to the formal caregivers, as they were considered best informed proxies. With regard to HA, caregivers were asked: "since the last visit, was the person with dementia admitted to a hospital (for more than 24 hours)?"; "how many times was your relative/the resident hospitalised?"; "for each hospitalisation, please provide the diagnosis or reasons for hospitalisation"; "for each hospitalisation, please specify the total number of nights spent in each type of ward". The following types of ward were asked about: geriatric ward, surgery ward, internal medicine ward, psychiatry ward and other hospital stays. If the answer "other" was given, the caregiver was asked to specify the type of ward by means of an open question. With regard to EDA, caregivers were asked: "Since the last visit, did the person with dementia receive care in an accident and emergency hospital department (for less than 24 hours)?"; and if yes, "how many times"? Participants with at least one episode of HA or EDA were considered to have experienced a hospital visit.

\section{Estimate of cost for emergency department and hospital admissions}

While the costs of dementia were previously measured from a societal perspective in the RTPC project [33-35], our study focused on the assessment of direct medical costs generated by EDA and HA and calculated as average costs per capita and year in Euros $(€)$. In the absence of valid and comparable unit costs for all participating countries, a common price vector based mainly on Swedish sources was used for all countries [33, 36]. For $\mathrm{HA}$, the length of stay in each medical department was taken into account in the measurement. In the case of fees not being available for daily stay in departments other than internal medicine, geriatrics or surgery it was decided to assume a cost per day similar to the daily expense in the department of geriatrics. In addition, we calculated the average costs per capita and year specifically among those people with dementia who had suffered $\geq 1$ hospital admission. All costs were inflated to the year 2019 and currency conversion adjustments based on 2019 exchange rates were made for the non-EURO countries. Cost components, unit costs, the international adjustment schemes and their sources are shown in Table 1 [32, 36, 37].

\section{Statistical analyses}

The characteristics of people with dementia and their informal caregivers as well as the HA and EDA episodes are described using means and standard deviations (SD) for continuous variables with normal distribution, median, first and third quarter for continuous variables without normal distribution, and percentages for discrete variables. The assessment of the hospitalisation rates was made taking into account the estimated annual emergency department and hospital admissions, respectively, in addition to the total number of people with dementia participating in the study.

Univariate analyses were used to evaluate the independent variables (CCI, S-MMSE, Katz Index, NPI-Q scores, ZBI, weight loss, polypharmacy, falls and setting) potentially associated with the occurrence of a Hospital Admission (at least one episode of HA or EDA). Variables were chosen after literature-based team discussion. Mann-Whitney's U test was used for continuous variables, as the distribution of the variables was not normal and the number of cases was small. Fisher's exact test was preferred when the software was available to calculate it (all categorical variables except country), even though the approximation using the Chi-square test was good because of sufficient sample size in all categories [38]. All variables were included in a logistic regression model. The different independent variables were tested on multicollinearity in order to identify potential interactions between them. 
Table 1 Unit costs and international price adjustments (inflated to the year 2019 ${ }^{\mathrm{a}}$ )

\begin{tabular}{|c|c|c|c|c|c|c|c|c|}
\hline & Estonia & Finland & France & Germany & Netherlands & Spain & Sweden & UK \\
\hline \multicolumn{9}{|l|}{ International price adjustment } \\
\hline Exchange rates; local currency / Euro & 1.00 & 1.00 & 1.00 & 1.00 & 1.00 & 1.00 & 10.59 & 0.87 \\
\hline \multicolumn{9}{|l|}{ Medical Care (Inpatient care) } \\
\hline Costs $^{\mathrm{b}}$ per day hospital (geriatric) & 92.14 & 318.60 & 313.82 & 293.41 & 280.82 & 162.22 & 335.25 & 256.98 \\
\hline Costs per day hospital (internal medicine) & 101.27 & 350.18 & 344.92 & 322.50 & 308.64 & 179.13 & 368.50 & 282.45 \\
\hline Costs per day hospital (surgery) & 148.87 & 514.74 & 507.01 & 474.05 & 453.69 & 263.31 & 541.63 & 415.19 \\
\hline Costs Emergency room visit & 63.06 & 218.14 & 214.86 & 200.89 & 192.27 & 111.59 & 229.54 & 175.94 \\
\hline
\end{tabular}

${ }^{a}$ Last available official statistics by the Organisation for Economic Co-operation and Development (OECD). Prices, purchasing power parities (PPP) and Exchange rates [32]

${ }^{\mathrm{b}}$ Costs are expressed in Euros

All analyses considered a significance level $\alpha$ of 0.05 (two-sided) and were conducted with IBM SPSS Statistics version 25 (IBM Corporation, Chicago, IL).

\section{Results}

\section{Sample characteristics}

The total RTPC sample at baseline comprised 2014 dyads of people with dementia and their informal caregivers. For the present study, only participants with data available on EDA and HA were included. Thus, the study sample comprised 1700 people with dementia and their informal caregivers $(n=1054(62 \%)$ from the HC setting and $n=646$ (38\%) from the NH setting).

The mean age of the study sample was 82.8 years (standard deviation (SD) 6.5), and 68.5\% were women. The characteristics of the study participants (people with dementia and informal caregivers) are summarized in Table 2 and Additional file 1, respectively.

\section{Emergency department or hospital admissions}

Table 3 describes the frequencies of EDA and HA in both settings as well as, for HA, the frequencies of admission and the average length of stay in days in the different medical departments evaluated.

Two-hundred and eighty-four of the people with dementia $(16.7 \%)$ experienced at least one EDA $(<24 \mathrm{~h})$ or HA between the baseline and follow-up assessments, with a higher frequency in the HC group $(\mathrm{NH}: 89$ (13.8\%) vs HC: 195 (18.5\%); $p=0.011)$. The majority of the people with dementia living at home and in nursing home who suffered at least one EDA within the 3 months had only one episode of EDA, with a minority of them suffering two or more EDA. A similar situation occurred for HA episodes.

We found an overall estimated HA rate per person with dementia/year of 0.44 and EDA rate per person with dementia/year of 0.37 , with an estimated rate of HA per person with dementia/year of 0.35 among persons living in $\mathrm{NH}$ and 0.50 among those living in $\mathrm{HC}$, and an estimated rate of EDA per person with dementia/year of 0.26 among persons living in $\mathrm{NH}$ and 0.43 among those living in $\mathrm{HC}$.

Some differences were found with regard to the types of departments where people with dementia were admitted, depending on their living situations.

\section{Factors associated with emergency department and hospital admissions}

Table 4 displays the univariate and multivariate analyses on the factors potentially associated with having at least one EDA or HA for each setting. The multivariate analyses showed that, for people with dementia living in $\mathrm{NH}$, polypharmacy was associated with having at least one EDA or HA (OR 1.96, CI (1.03-3.75)). With regard to the people with dementia living in $\mathrm{HC}$, the factors independently associated with hospital admission were: the presence of falls in the preceding 3 months (OR 1.64, CI (1.12-2.41)), polypharmacy (OR 2.48, CI (1.70-3.62)), weight loss (OR 1.73, CI (1.17-2.56)), mild caregiver burden compared with little or no burden (OR 1.67 CI (1.04-2.66)), and moderate to severe caregiver burden compared with little or no burden (OR 1.76, CI (1.04$2.98)$ ). No statistically significant association was found between hospital admission and functional or cognitive status of participants in either $\mathrm{NH}$ or $\mathrm{HC}$.

\section{Costs of emergency department and hospital admissions}

Table 5 shows the estimated health cost per person with dementia/year according to country and setting ( $\mathrm{NH}$ vs $\mathrm{HC}$ ). On average, for the whole study sample, the estimated medical cost per person with dementia/year related to EDA and HA was $1884.28 €$, with $1046.19 €$ per person with dementia/year in NH group and 2397.96€ in HC group. Concerning the estimated average expenditure per person with dementia/year for EDA, this was $67.30 €$ in the $\mathrm{NH}$ group and $117.48 €$ in the $\mathrm{HC}$ group. For HA an estimated average cost per person with dementia/year of $978.89 €$ was obtained in the $\mathrm{NH}$ group, and $2280.48 €$ in the HC group. On average, for the whole study sample, we found higher expenses per 
Table 2 Baseline characteristics of the people with dementia, by setting

\begin{tabular}{|c|c|c|c|}
\hline Variables & $\begin{array}{l}\text { Nursing Home } \\
(n=646)\end{array}$ & $\begin{array}{l}\text { Home Care } \\
(n=1054)\end{array}$ & $\begin{array}{l}\text { Overall } \\
(n=1700)\end{array}$ \\
\hline Age (years), mean (SD) & $83.8(6.5)$ & $82.1(6.5)$ & $82.8(6.5)$ \\
\hline Women, n (\%) & $486(75.2 \%)$ & $679(64.4 \%)$ & $1165(68.5 \%)$ \\
\hline S- MMSE (range $0-\underline{30})^{a},{ }^{b}$, median $(\mathrm{Q} 1 ; Q 3)$ & $13(8 ; 17)$ & $15(10 ; 20)$ & $14(9 ; 19)$ \\
\hline Missing values & 128 & 130 & 258 \\
\hline Katz Index (range $0-\underline{6})^{\mathrm{a}}$, median $(\mathrm{Q} 1 ; \mathrm{Q} 3)$ & $2(1 ; 4)$ & $3(2 ; 5)$ & $3(1 ; 5)$ \\
\hline Missing values & 2 & 11 & 13 \\
\hline Charlson Comorbidity Index (range $\underline{0}-37)^{\mathrm{a}}$, median (Q1;Q3) & $2(1 ; 3)$ & $2(1 ; 3)$ & $2(1 ; 3)$ \\
\hline Severity of neuropsychiatric symptoms (range $\underline{0}-36)^{a}$, median $(\mathrm{Q} 1 ; \mathrm{Q} 3)$ & $5.5(3 ; 10)$ & $8(4 ; 13)$ & $7(3 ; 12)$ \\
\hline Zarit Burden Interview (range $\underline{0}-88)^{\mathrm{a}}$, median $(\mathrm{Q} 1 ; \mathrm{Q} 3)$ & $21(13 ; 33)$ & $31(20.9 ; 43)$ & $27(17 ; 39.2)$ \\
\hline Missing values & 3 & 3 & 6 \\
\hline Weight loss ( $\geq 4 \%$, yes), n (\%) & $81(13.0 \%)$ & $211(20.6 \%)$ & $292(17.7 \%)$ \\
\hline Missing values & 25 & 28 & 53 \\
\hline Polypharmacy ( $\geq 5$ drugs, yes), n (\%) & $440(68.1 \%)$ & $604(57.3 \%)$ & $1044(61.4 \%)$ \\
\hline Mean number of drugs (SD) & $6.0(3.1)[6]$ & $5.3(3.1)[5]$ & $5.5(3.1)[5]$ \\
\hline Falls in preceding 3 months (baseline) & $172(26.7 \%)$ & $215(20.4 \%)$ & $387(22.8 \%)$ \\
\hline Missing values & 3 & 1 & 4 \\
\hline \multicolumn{4}{|l|}{ Country, n (\%) } \\
\hline United Kingdom & 55 (8.5\%) & 60 (5.7\%) & 115 (6.8\%) \\
\hline Estonia & 80 (12.4\%) & 145 (13.8\%) & $225(13.2 \%)$ \\
\hline Finland & $111(17.2 \%)$ & 157 (14.9\%) & $268(15.8 \%)$ \\
\hline France & 35 (5.4\%) & $151(14.3 \%)$ & $186(10.9 \%)$ \\
\hline Germany & 99 (15.3\%) & 91 (8.6\%) & 190 (11.2\%) \\
\hline Netherlands & $104(16.1 \%)$ & 165 (15.7\%) & 269 (15.8\%) \\
\hline Spain & 85 (13.2\%) & 155 (14.7\%) & $240(14.1 \%)$ \\
\hline Sweden & 77 (11.9\%) & $130(12.3 \%)$ & $207(12.2 \%)$ \\
\hline
\end{tabular}

Missing values declared when present

SD Standard Deviation, Q1 First quartile, Q3 Third quartile

${ }^{a}$ Underlined scores indicate the direction of a better outcome

${ }^{b}$ Only participants with scores of lower than 24 points were included

person with dementia/year in both ED and HA visits for people with dementia living in the $\mathrm{HC}$ setting compared to those living in the $\mathrm{NH}$ setting, except in the Netherlands, where a higher expenditure on hospitalisation of people with dementia living in $\mathrm{NH}$ was found, despite the global EDA and HA cost per person with dementia/year being lower than the $\mathrm{HC}$ group. A greater estimated cost per person with dementia/year for EDA was also found in the $\mathrm{NH}$ group in France and Germany.

\section{Discussion}

In this cross-sectional study, 1700 people with dementia from eight European countries participating in the RTPC study were investigated. The estimated rate of hospital admission per person with dementia/year of 0.35 among people living in $\mathrm{NH}$ and 0.50 among those living in $\mathrm{HC}$, and an estimated rate of emergency department admission per person with dementia/year of 0.26 among people living in $\mathrm{NH}$ and 0.43 among those living in $\mathrm{HC}$. In the $\mathrm{HC}$ setting, factors identified as being associated with a higher probability of suffering at least one EDA or HA were: suffering weight loss, accidental falls, presenting polypharmacy and having a caregiver with mild to severe burden compared with little or no burden. In the $\mathrm{NH}$ setting, only polypharmacy was associated with a higher probability of suffering at least one EDA or HA. Concerning health costs, a higher estimated cost per person/year attributable to hospital admission (EDA and HA) was observed for people with dementia included in the $\mathrm{HC}$ group as compared to the $\mathrm{NH}$ group.

With regard to community-dwelling people with dementia, our results of estimated rate of hospitalisation are within the range of hospitalization rates presented by Shepherd et al. in their systematic review of the literature (rates of 0.37-1.26 per person/year) [9]. When 
Table 3 Description of Emergency Department Admissions (EDA) and Hospital Admission (HA), by setting

\begin{tabular}{|c|c|c|c|c|}
\hline & Nursing Home $(n=646)$ & Home Care $(n=1054)$ & Overall $(n=1700)$ & $p_{\text {__value }}^{* * * *}$ \\
\hline PwD* with at least $1 \mathrm{EDA}$ or $1 \mathrm{HA}^{* *}, \mathrm{n}(\%)$ & $89(13.8 \%)$ & $195(18.5 \%)$ & $284(16.7 \%)$ & 0.011 \\
\hline PwD with at least 1 EDA (with < 24 h stay), n (\%) & $48(7.4 \%)$ & $123(11.7 \%)$ & $171(10.1 \%)$ & 0.005 \\
\hline PwD with valid number of EDA*** & 43 & 115 & 158 & \\
\hline PwD with 1 admission, n (\%) & $33(76.7 \%)$ & $81(70.4 \%)$ & $114(72.2 \%)$ & \\
\hline PwD with 2 or more admissions, $\mathrm{n}(\%)$ & $10(23.3 \%)$ & $34(29.6 \%)$ & $44(27.8 \%)$ & \\
\hline Rate of EDA per PwD/year & 0.26 & 0.43 & 0.37 & \\
\hline PwD with at least $1 \mathrm{HA}$ (with > $24 \mathrm{~h}$ stay), $\mathrm{n}(\%)$ & $58(9.0 \%)$ & $135(12.8 \%)$ & $193(11.4 \%)$ & 0.018 \\
\hline PwD with valid number of $\mathrm{HA}^{* * *}$ & 57 & 133 & 190 & \\
\hline PwD with 1 admission, n (\%) & $50(87.7 \%)$ & $103(77.4 \%)$ & $153(80.5 \%)$ & \\
\hline PwD with 2 or more admissions, n (\%) & $7(12.3 \%)$ & $30(22.6 \%)$ & $37(19.5 \%)$ & \\
\hline Rate of HA per PwD/year & 0.35 & 0.50 & 0.44 & \\
\hline \multicolumn{5}{|l|}{ Department of HA, n (\%) } \\
\hline Geriatric & $5(10 \%)$ & $49(35 \%)$ & $54(28 \%)$ & \\
\hline Internal Medicine & $15(31 \%)$ & $41(29 \%)$ & $56(29 \%)$ & \\
\hline Surgical & $20(41 \%)$ & $20(14 \%)$ & $40(21 \%)$ & \\
\hline Other & $11(22 \%)$ & $30(21 \%)$ & $41(22 \%)$ & \\
\hline \multicolumn{5}{|c|}{ Length of stay during HA admission in days, median $(\mathrm{Q} 1 ; \mathrm{Q} 3)$} \\
\hline Geriatric & $8(5 ; 16)$ & $8(6 ; 11)$ & $7.5(6 ; 11)$ & \\
\hline Internal Medicine & $11(4 ; 15)$ & $8(6 ; 17)$ & $7.5(5 ; 17)$ & \\
\hline Surgical & $6.5(3 ; 17)$ & $8.5(4 ; 11)$ & $7(3 ; 15)$ & \\
\hline Other & $3(2 ; 6)$ & $9(6 ; 18)$ & $7(4 ; 14)$ & \\
\hline
\end{tabular}

Note: Q1 first quartile, Q3 third quartile

*: PwD: People with Dementia

**: A PwD may have suffered both EDA and HA episodes

***: Data on the number of EDA or HA available only for these participants

${ }^{* * * *}$ : $p$ values provided only for the main descriptive variables on EDA and HA

comparing our results on hospitalisation rates among people with dementia living in $\mathrm{NH}$, the few studies existing for this setting report on disparing results, with Maxwell et al. (2018) reporting a rate of 0.21 person/year [10], and Feng et al. (2014) reporting a rate of 0.46 [39].

People with dementia living at their homes had higher rates of EDA or HA than those in the $\mathrm{NH}$ setting in the present study. Reasons for this may have been that caregivers of people with dementia who live at home may have had less support in managing health needs or higher levels of care burden [40], leading to a greater need for emergency service utilization and hospital admission. Other reasons for lower hospital transfer needs in the nursing home setting compared with home care suggested in the literature are that, even if EDA rates from nursing home are high [8], some of these institutions may be equipped with specific care units for people with advanced dementia [41], have a wider availability to perform post-acute attention [42], receive specialized health support from geriatric [43] or end-of-life care more frequently, and they may have policies to prevent transferring those persons to hospital.
Sleeman et al. also found in a retrospective cohort study of 4867 people with dementia in their last year of life in England, that being in a nursing home was associated with a significantly lower number of ED visits [43]. The authors argued that increasing bed capacity in NHs may have explained their results, as it may have allowed more people with advanced dementia dying in the $\mathrm{NH}$.

Maxwell et al. also reported on lower hospitalisation rates among people with dementia living in $\mathrm{NH}$ compared with those living in assisted living facilities, and attributed this difference to the insufficient capacity of assisted living facilities to cover the needs of people with dementia [10].

Conversely, another report analyzing the impact of dementia on hospital and ED use among fee-for-service Medicare beneficiaries reported that people with dementia who lived in nursing homes were significantly more likely to visit the emergency department and be hospitalised than those who resided in their own homes [29].

In the $\mathrm{HC}$ setting, polypharmacy was associated with hospital admission, in the line with the results by Shepherd et al., who found moderate confidence in this 


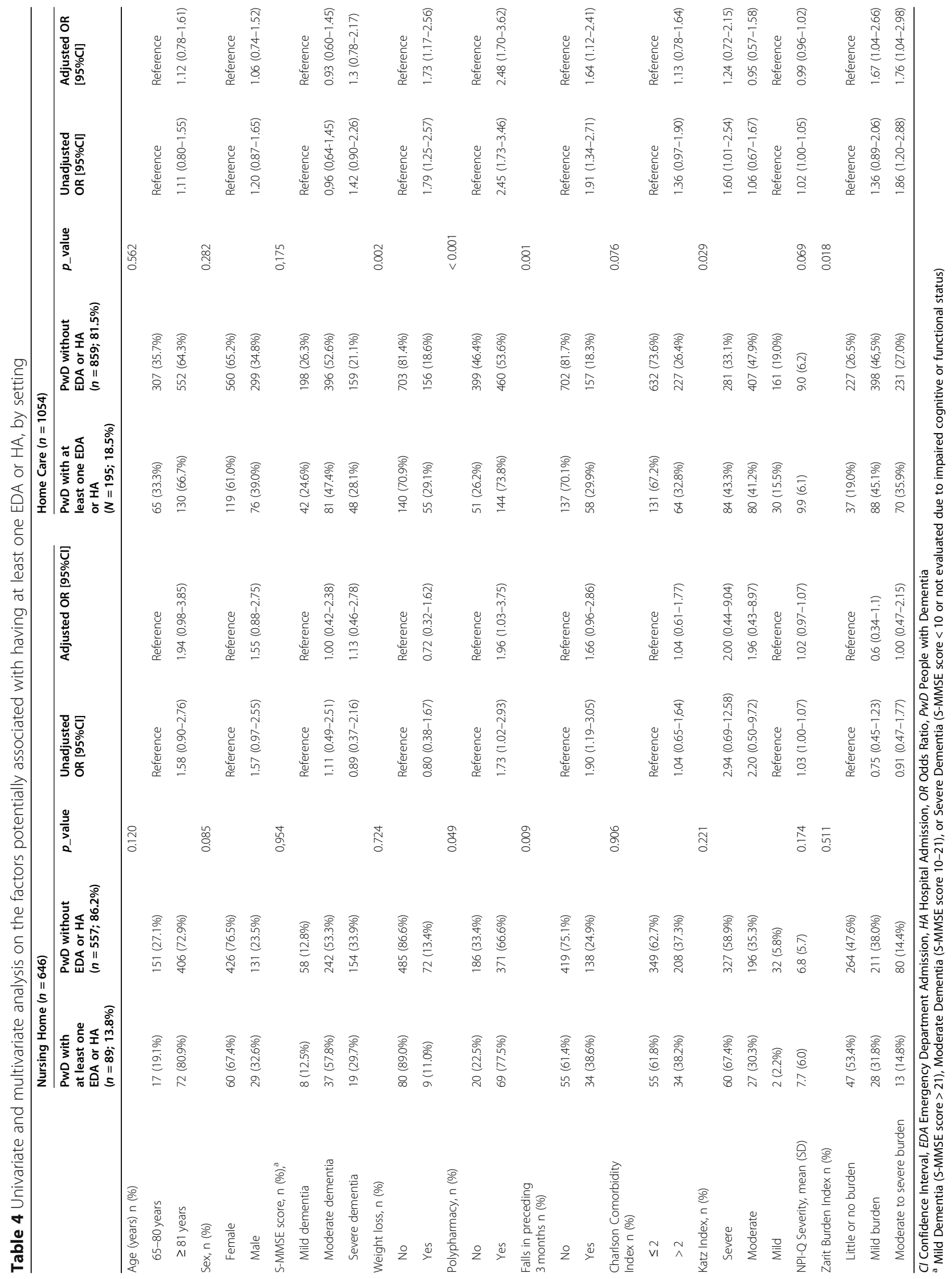


Table 5 Estimated average annual medical costs per person with dementia in the RTPC sample $(n=1700){ }^{a}, b, c$

\begin{tabular}{|c|c|c|c|c|c|c|c|c|c|}
\hline Medical Care (Inpatient care) & $\begin{array}{l}\text { Estonia } \\
n=225\end{array}$ & $\begin{array}{l}\text { Finland } \\
n=268\end{array}$ & $\begin{array}{l}\text { France } \\
n=186\end{array}$ & $\begin{array}{l}\text { Germany } \\
n=190\end{array}$ & $\begin{array}{l}\text { Netherlands } \\
n=269\end{array}$ & $\begin{array}{l}\text { Spain } \\
n=240\end{array}$ & $\begin{array}{l}\text { Sweden } \\
n=207\end{array}$ & $\begin{array}{l}\text { UK } \\
n=115\end{array}$ & $\begin{array}{l}\text { All countries } \\
n=1700\end{array}$ \\
\hline $\begin{array}{l}\text { Estimated } \mathrm{n} \text { of people with } \\
\text { dementia } \\
\text { with EDA episodes } \\
\text { (estimated EDA episodes/year) }\end{array}$ & $48(56)$ & $124(164)$ & $56(68)$ & $84(108)$ & $72(144)$ & $136(200)$ & $36(108)$ & $76(96)$ & $632(944)$ \\
\hline Cost (NH) & 6.31 & 62.89 & 122.78 & 121.75 & 51.77 & 52.51 & 35.77 & 127.96 & 67.30 \\
\hline Cost (HC) & 20.87 & 183.41 & 68.30 & 105.96 & 135.17 & 115.19 & 169.51 & 164.21 & 117.48 \\
\hline Total cost of EDA & 15.69 & 133.49 & 78.55 & 114.19 & 102.93 & 92.99 & 119.76 & 146.87 & 98.41 \\
\hline $\begin{array}{l}\text { Estimated } n \text { of people with } \\
\text { dementia } \\
\text { with HA episodes } \\
\text { (estimated HA days/year) }\end{array}$ & $72(816)$ & $148(2656)$ & $176(1832)$ & $140(1072)$ & $44(204)$ & $56(1012)$ & $56(1308)$ & $72(1000)$ & 764 (9900) \\
\hline Cost (NH) & 215.86 & 1092.88 & 1326.99 & 1464.11 & 353.11 & 397.94 & 2005.59 & 1229.82 & 978.89 \\
\hline Cost $(\mathrm{HC})$ & 459.23 & 5340.47 & 3632.84 & 2429.68 & 153.14 & 1372.76 & 3028.60 & 1619.27 & 2280.48 \\
\hline Total cost of HA & 372.70 & 3581.21 & 3198.94 & 1926.57 & 238.17 & 1059.53 & 2648.13 & 1433.01 & 1785.87 \\
\hline $\begin{array}{l}\text { Estimated } n \text { of people with } \\
\text { dementia } \\
\text { with hospital episodes } \\
\text { (EDA episodes and HA episodes) }\end{array}$ & 120 & 272 & 232 & 224 & 116 & 192 & 92 & 148 & 1396 \\
\hline Cost (NH) & 222.17 & 1155.77 & 1449.77 & 1585.86 & 424.83 & 540.84 & 2041.56 & 1357.78 & 1046.19 \\
\hline Cost $(\mathrm{HC})$ & 480.10 & 5523.87 & 3701.13 & 2535.65 & 288.31 & 1487.96 & 3198.11 & 1783.48 & 2397.96 \\
\hline Total cost of hospital episodes & 388.39 & 3714.70 & 3277.49 & 2040.76 & 341.09 & 1152.52 & 2767.89 & 1579.89 & 1884.28 \\
\hline
\end{tabular}

EDA Emergency Department Admissions, HA Hospital Admissions

${ }^{a}$ All expenses refer to costs per person with dementia, according to setting and country

${ }^{\mathrm{b}}$ Costs calculated including only people with dementia with data available on the number of EDA or HA

${ }^{c}$ All costs expressed in $€$

association in their meta-analysis [9]. In contrast, Shepherd et al. found moderate confidence in the association of lower level of functional ability with hospitalisation risk. This association was not found in the present study. Instead, in the present study significant associations were found with a history of falls within the previous 3 months and with the presence of weight loss. These factors were not evaluated by Shepherd et al. in their meta-analyses. Interestingly, the authors suggest in their discussion that it can be difficult to ascertain whether loss of functionality may be connected with other adverse outcomes such as side effects of medication or even malnutrition or weight loss. This might explain the differences between their results and those of the present study.

So far, unintentional weight loss has been found associated with increased morbidity and mortality among older adults [44], but to the best of our knowledge the relationship between unintentional weight loss in people with dementia and the risk of hospitalisation has not been well established $[9,45]$. In previous reports, but in older populations, malnutrition has been associated with an almost fourfold increased risk of readmission or mortality within 7 days of discharge from a hospital, and the risk almost doubled between 8 and 180 days after discharge [46].
Conversely, falls are of great concern for people with dementia given their potentially higher number of visits to emergency departments and severe consequences, mainly hip fracture [47]. Our results are aligned with those reported by Toot et al. on the risk of admission associated with osteoarticular conditions (eg: falls/fractures) in people with dementia living in the community [48].

The severity of dementia was not associated with hospital admission, which is consistent with the results presented by Shepherd et al. in their meta-analyses, who reported moderate confidence in this finding [9].

Conversely, higher comorbidity was not associated with hospital admission in the present study, in contrast with the results by Shepherd et al., who graded their confidence with this result as moderate. However, in their discussion, the authors reported on a study [49] that described an increased risk of hospitalisation only because of the presence of dementia as comorbidity, irrespective of the existence of any further comorbid conditions.

Currently, evidence for effective interventions to reduce the risk of falls, to reduce polypharmacy and to improve nutrition is limited and requires further development [50-53]. Nevertheless, the results of the present study suggest that the identification and 
management of these three geriatric syndromes might help preventing hospitalisation events among people with dementia living at home. Furthermore, the promotion of an advanced and individualised care plan among people with dementia showing these geriatric syndromes may be particularly advisable.

Mild to severe levels of caregiver burden were associated with hospital admission for people with dementia living in the $\mathrm{HC}$ setting in the present study. This result is in the line with the results by Guterman et al. [14] and Maust et al. [40], which found a significant association between mental health and caregiver distress, respectively, and ED use by people with dementia living in the community. Future interventions to reduce unnecessary hospitalisations should also focus on providing support to the caregivers of people with dementia living at home.

In the $\mathrm{NH}$ setting, only polypharmacy was associated with hospital admission among people with dementia in the present study, suggesting that there is a special need to target this geriatric syndrome for this population, in order to reduce unnecessary hospitalisations $[54,55]$.

In the present study, it was observed that medical costs associated with hospital admission (including EDA) were higher in the $\mathrm{HC}$ setting, results that can be explained by the higher frequency of HA and EDA found among people with dementia living at home. Similar to our results, Coots Daras et al. (2017) found that people with dementia in their last year of life living in $\mathrm{NH}$ had lower costs derived of EDA and HA than people with dementia living in the community. However, these results were not seen among the general population with dementia, for whom the costs of EDA and HA were higher among those living in $\mathrm{NH}$ [16]. The authors discuss that expenditures associated with hospital and ED use may vary by residential setting, and proximity to death.

Our results suggest that interventions aimed at preventing EDA and $\mathrm{HA}$ among people with dementia may be cost-effective, especially in the HC setting, as for most countries the costs associated with EDA and HA were higher in these setting. However, the results should be interpreted with caution, as costs of other interventions that may be put in place when acute events occur such as specialized health support teams or specific care units for advanced dementia have not been taken into consideration. Differences between countries with regard to the implementation of such interventions, as well as potential country differences in the characteristics of the people with dementia living in each of the settings [56] and potential country differences in the way how dementia care is provided [57], may explain the country differences seen in the costs of hospitalisation. Furthermore, these results should be seen within the framework of the overall costs of dementia care. Interestingly, a previous analysis of the costs of dementia care within the RTPC study showed higher costs for the care provided at $\mathrm{NH}$ compared with those provided at $\mathrm{HC}$, with the particularity that the costs in the $\mathrm{HC}$ setting increased with the severity of dementia [33].

The findings of our study should be interpreted considering its limitations. Firstly, there might have been a number of people with undiagnosed dementia who were not included in the present study due to its inclusion criteria (formal diagnosis of dementia); these people, who may also be admitted to hospital for several reasons with the corresponding costs associated, could not be described in the present study. Secondly, the time period investigated for each participant was limited to 3 months, which may not represent the entire population of people with dementia requiring hospital admission over the one-year period, taking into account seasonal fluctuations; however, the prospective character of the study may have facilitated the acquisition of reliable data. Furthermore, the RTPC country samples may not be representative of the general national population of people with dementia. Thirdly, although we accounted for multiple variables that may affect the need for hospital admission, there may also be additional unmeasured confounding factors that influence the use of hospital care, for example, specific health support at the community or nursing home setting in each country or even at the local level. Finally, several years have passed between data compilation and secondary analysis. However, we believe that the present study adds relevant value to the body of literature with regard to the comparison of the frequency of hospitalisation between the $\mathrm{NH}$ and $\mathrm{HC}$ settings among people with dementia, factors associated and costs, in a world where the organization of long-term-care is still a challenge [58].

\section{Conclusions}

To the best of our knowledge, this is the first study that evaluates internationally (across Europe) the frequency of hospitalisation among people with dementia living in nursing homes and home care settings, and analyses the associated factors and costs for each setting.

Admission to hospital is frequent among people with dementia, especially among those living in the community, and seems to impose a remarkable economic burden. The identification and establishment of an individualized care plan for those people with dementia with polypharmacy in nursing homes, and those with involuntary weight loss, accidental falls, polypharmacy and higher caregiver burden in the home care setting, might help preventing unnecessary hospital admissions and saving associated costs. 


\section{Supplementary information}

Supplementary information accompanies this paper at https://doi.org/10. 1186/s12877-020-01835-x.

Additional file 1: Baseline characteristics of informal caregivers.

\section{Abbreviations}

CCl: Charlson Comorbidity Index; COI: Cost-of-illness; EDA: Emergency Department Admission; €: Euros; EU: European Union; HA: Hospital Admission; IEA: International Epidemiological Association; KATZ: Katz Index of Independence in Activities in Daily Living; NH: Nursing Home; NPIQ: Neuropsychiatric Inventory-Questionnaire; OECD: Organisation for Economic Co-operation and Development; OR: Odds Ratio; PPP: Purchasing Power Parities; Q1: Quartile 1; Q2: Quartile 2; RTPC: RightTimePlaceCare; RUD: Resource Utilization in Dementia; SD: Standard Deviation; SMMSE: Standardized Mini-Mental State Examination; WHO: World Health Organization; ZBI: Zarit Burden Interview

\section{Acknowledgements}

We thank Robert Schmitz for his previous work analyzing transfer episodes among the participants of the RTPC study. We appreciate the collaboration of Georgina Ramírez Rodríguez, M.D. for her support at the cost estimations shown in the study.

Group authorship

The RightTimePlaceCare (RTPC) Consortium partners are as follows: Coordinator

University of Witten/Herdecke (DE): Gabriele Meyer PhD, RN, professor (scientific coordinator, WP 1 leader), Astrid Stephan PhD, RN, Anna RenomGuiteras PhD, Dirk Sauerland, professor (WP 4 and 6 leader), Dr. Ansgar Wübker PhD, Patrick Bremer.

Consortium members

Maastricht University (NL): Jan P.H. Hamers PhD, RN; Basema Afram MSc, Hanneke C. Beerens PhD, RN; Michel H.C. Bleijlevens, PhD, PT; Hilde Verbeek, PhD; Sandra M.G. Zwakhalen, PhD, RN; Dirk Ruwaard, MD, Ton Ambergen, PhD.

Lund University (SE): Ingalill Rahm Hallberg PhD, RN; Ulla Melin Emilsson PhD; Staffan Karlsson, PhD, RN; Christina Bokberg, PhD, RN; Connie Lethin, $\mathrm{PhD}, \mathrm{RN}$.

University of Manchester (UK): David Challis, PhD, professor; Caroline Sutcliffe, MSc; David Jolley, PhD; Sue Tucker, MSc, RN; Ian Bowns, PhD; Brenda Roe, PhD; Alistair Burns, PhD, professor.

University of Turku (FI): Helena Leino-Kilpi, PhD, RN, professor; Jaana Koskenniemi, MNSc, RN, researcher; Riitta Suhonen, PhD, RN, professor; Matti Viitanen, MD, PhD, professor; Seija Arve, PhD, RN, adjunct professor; Minna Stolt, MNSc; Maija Hupli, PhD, RN.

University of Tartu (EE): Kai Saks, MD, PhD, professor; Ene-Margit Tiit, PhD, professor; Jelena Leibur, MD, MBA; Katrin Raamat, MA; Angelika Armolik, MA; Teija Tuula Marjatta Toivari, RN.

Fundació Privada Clinic per la Recerca Biomedica, Hospital Clinic of Barcelona (ES): Adelaida Zabalegui, PhD, RN, FEANS (WP 5 leader); Montserrat Navarro, PhD, RN; Esther Cabrera, PhD, RN (Tecnocampus Mataró); Ester Risco, PhD, RN; Carme Alvira, PhD, RN; Marta Farré, MSc, RN; Susana Miguel, MSc, RN. Gerontôpole, University of Toulouse (FR): Maria Soto, MD; Agathe Milhet; Sandrine Sourdet, MD; Sophie Gillette; Bruno Vellas, PhD.

\section{Authors' contributions}

ARG, FJAA and GM contributed to the conception, design of the work, analysis and interpretation of data of the present study. MC contributed to the analysis of data. AW contributed to the design of the work. ARG, GM, AW, AS, HLK, CL, KS, MSM, CS, HV and AZ contributed to the conception, design of the work, acquisition of data for the RTPC study. FJAA prepared the first draft of the manuscript, supported by ARG. All authors critically reviewed and approved the final manuscript.

\section{Funding}

The RightTimePlaceCare study was supported by a grant from the European Commission within the 7th Framework Program (project 242153). The funder played no role in the design of the study and collection, analysis, and interpretation of data and in writing the manuscript. Open Access funding enabled and organized by Projekt DEAL.

\section{Availability of data and materials}

The datasets used and/or analysed during the current study are available from the corresponding author on reasonable request.

\section{Ethics approval and consent to participate}

The Good Epidemiological Practice guidelines recommended by the International Epidemiological Association (IEA 2007) and the Helsinki declaration are followed. This study was approved by the Ethical Committee of the Hospital Clinic, Barcelona, Spain (2010/6031); the Ethics Review Committee on Human Research of the University of Tartu (196/T-3) and the Ethical Committee of the Hospital District of South-West Finland (8/2010), Finland; the Comité de Protection des Personnes Sud-Ouest et Outre-Mer, Toulouse, France (09 202 07); the Nursing Science Ethical Committee at the University of Witten/Herdecke, Germany; the Medical Ethical Committee of the Academic Hospital Maastricht/Maastricht University, the Netherlands (MEC 10-5-044); the Regional Ethical Review Board in Lund, Sweden (2010/ 538); and the National Research Ethics Service, North West 5 Research Ethics Committee, the United Kingdom (11/NW/0003) (Verbeek et al., 2012). Participants were informed of the study purpose, and they were free to participate or withdraw from the study at any time. They were asked to sign the informed consent form.

\section{Consent for publication}

Not applicable.

\section{Competing interests}

The authors declare that they have no competing interests.

\section{Author details}

${ }^{1}$ Department of Geriatric Medicine and Palliative Care. Badalona Serveis Assistencials, Barcelona, Spain. ${ }^{2}$ Universitat Autònoma de Barcelona, Barcelona, Spain. ${ }^{3}$ Department of Nursing Science, Witten/Herdecke University, Witten, Germany. ${ }^{4}$ Institute of Health and Nursing Sciences, Medical Faculty, Martin Luther University Halle-Wittenberg, Halle (Saale), Germany. ${ }^{5}$ Department of Epidemiology and Evaluation. Hospital del Mar, Parc de Salut Mar, Barcelona, Spain. ${ }^{6}$ Member of the Health Services Research on Chronic Patients Network (REDISSEC), Madrid, Spain. ${ }^{7} \mathrm{RWI}-$ Leibniz-Institute for Economic Research, Leibniz Science Campus Ruhr and RUB, Essen, Germany. ${ }^{8}$ Department of Nursing Science and Nurse Director, Turku University Hospital, University of Turku, Turku, Finland. ${ }^{9}$ Department of Health Sciences. Faculty of Medicine, Lund University, SE-221 00 Lund, Sweden. ${ }^{10}$ Clinical Memory Research Unit. Department of Clinical Sciences, Lund University, SE-221 00 Lund, Sweden. ${ }^{11}$ Department of Internal Medicine, University of Tartu, Tartu, Estonia. ${ }^{12}$ Department of Geriatric Medicine, Gerontopole, Alzheimer Disease Research Center, Inserm UMR 1027, University Hospital of Toulouse, Toulouse, France. ${ }^{13}$ School of Health Sciences, University of Manchester, Manchester, UK. ${ }^{14}$ Department of Health Services Research, Care and Public Health Research Institute, Maastricht University, Maastricht, The Netherlands. ${ }^{15}$ Living Lab in Ageing and Long-Term Care, Maastricht, The Netherlands. ${ }^{16}$ Hospital Clinic de Barcelona, Barcelona, Spain. ${ }^{17}$ School of Medicine, Universitat de Barcelona, Barcelona, Spain. ${ }^{18}$ Department of Geriatric Medicine, Parc de Salut Mar, Barcelona, Spain.

Received: 13 April 2020 Accepted: 14 October 2020 Published online: 05 November 2020

\section{References}

1. Nichols E, Szoeke CEl, Vollset SE, Abbasi N, Abd-Allah F, Abdela J, et al. Global, regional, and national burden of Alzheimer's disease and other dementias, 1990-2016: a systematic analysis for the global burden of disease study 2016. Lancet Neurol. 2019;18(1):88-106.

2. Caron CD, Ducharme F, Griffith J. Deciding on institutionalization for a relative with dementia: the Most difficult decision for caregivers. Can Aging. 2006;25(2):193-205.

3. Whittamore KH, Goldberg SE, Gladman JRF, Bradshaw LE, Jones RG, Harwood RH. The diagnosis, prevalence and outcome of delirium in a cohort of older people with mental health problems on general hospital wards. Int J Geriatr Psychiatry. 2014;29(1):32-40.

4. Hartley P, Gibbins N, Saunders A, Alexander K, Conroy E, Dixon R, et al. The association between cognitive impairment and functional outcome in 
hospitalised older patients: a systematic review and meta-analysis. Age Ageing. 2017;46(4):559-67.

5. Cameron ID, Dyer SM, Panagoda CE, Murray GR, Hill KD, Cumming RG, Kerse $\mathrm{N}$. Interventions for preventing falls in older people in care facilities and hospitals. Cochrane Database Syst Rev. 2018;(9):1-336. https://doi.org/10 1002/14651858.CD005465.pub4.

6. Bail K, Berry H, Grealish L, Draper B, Karmel R, Gibson D, Peut A. Potentially preventable complications of urinary tract infections, pressure areas, pneumonia and delirium in hospitalised dementia patients: retrospective cohort study. BMJ Open. 2013;3(6):1-8. https:/doi.org/10.1136/bmjopen-2013-002770.

7. Dwyer R, Gabbe B, Stoelwinder JU, Lowthian J. A systematic review of outcomes following emergency transfer to hospital for residents of aged care facilities. Age Ageing. 2014;43(6):759-66.

8. Graverholt B, Riise T, Jamtvedt G, Ranhoff AH, Krüger K, Nortvedt MW. Acute hospital admissions among nursing home residents: a population-based observational study. BMC Health Serv Res. 2011;11(1):126.

9. Shepherd H, Livingston G, Chan J, et al. Hospitalisation rates and predictors in people with dementia: a systematic review and metaanalysis. BMC Med. 2019:17(130):1-13. https://doi.org/10.1186/s12916-019-1369-7.

10. Maxwell CJ, Amuah JE, Hogan DB, Cepoiu-Martin M, Gruneir A, Patten SB, et al. Elevated hospitalization risk of assisted living residents with dementia in Alberta. Canada J Am Med Dir Assoc. 2015;16(7):568-77.

11. Yang Y, Lin M, Wang C, Lu F, Wu J, Cheng H, et al. Geriatric syndromes and quality of life in older adults with diabetes. Geriatr Gerontol Int. 2019;19(6):518-24.

12. Kane RL, Shamliyan T, Talley K, Pacala J. The association between geriatric syndromes and survival. J Am Geriatr Soc. 2012;60(5):896-904.

13. Lu F-P, Chang W-C, Wu S-C. Geriatric conditions, rather than multimorbidity, as predictors of disability and mortality among octogenarians: a populationbased cohort study. Geriatr Gerontol Int. 2016;16(3):345-51.

14. Guterman EL, Allen IE, Josephson SA, Merrilees JJ, Dulaney S, Chiong W, et al. Association between caregiver depression and emergency department use among patients with dementia. JAMA Neurol. 2019;76(10):1166-73.

15. Cantarero-Prieto D, Leon PL, Blazquez-Fernandez C, Juan PS, Cobo CS. The economic cost of dementia: A systematic review. London: Dementia; 2019. https://doi.org/10.1177/1471301219837776.

16. Daras LC, Feng Z, Wiener JM, Kaganova Y. Medicare expenditures associated with hospital and emergency department use among beneficiaries with dementia. Inq (United States). 2017:54:1-9.

17. Verbeek H, Meyer G, Leino-Kilpi H, Zabalegui A, Hallberg IR, Saks K, et al. A European study investigating patterns of transition from home care towards institutional dementia care: the protocol of a RightTimePlaceCare study. BMC Public Health. 2012;12(1):68.

18. Long-term Care for Older People. OECD; 2005. (The OECD Health Project).

19. Molloy DW, Alemayehu E, Roberts R. Reliability of a standardized minimental state examination compared with the traditional mini-mental state examination. Am J Psychiatry. 1991;148(1):102-5.

20. Molloy DW, Standish TIM. A guide to the standardized mini-mental state examination. Int Psychogeriatr. 1997;9(S1):87-94.

21. Charlson ME, Pompei P, Ales KL, Mackenzie CR. A new method of classifying prognostic comorbidity in longitudinal studies: development and validation. J Chronic Dis. 1987:40(5):373-83.

22. Katz S, Ford AB, Moskowitz RW, Jackson BA, Jaffe MW. The index of ADL: a standardized measure of biological and psychosocial function. J Am Med Assoc. 1963;185(12):914-9.

23. Kaufer DI, Cummings JL, Ketchel P, Smith V, MacMillan A, Shelley T, et al. Validation of the NPI-Q, a brief clinical form of the neuropsychiatric inventory. J Neuropsychiatry Clin Neurosci. 2000;12(2):233-9.

24. Du Moulin MFMT, van Haastregt JCM, Hamers JPH. Monitoring quality of care in nursing homes and making information available for the general public: state of the art. Patient Educ Couns. 2010;78(3):288-96.

25. McMinn J, Steel C, Bowman A. Investigation and management of unintentional weight loss in older adults. BMJ. 2011;342:d1732.

26. Jensen GL, Cederholm T, Correia MITD, Gonzalez MC, Fukushima R, Higashiguchi T, et al. GLIM criteria for the diagnosis of malnutrition: a consensus report from the global clinical nutrition community. J Parenter Enter Nutr. 2019:43(1):32-40.

27. Masnoon N, Shakib S, Kalisch-Ellett L, Caughey GE. What is polypharmacy? A systematic review of definitions. BMC Geriatr. 2017;17(1):230.

28. Lamb SE, Jørstad-Stein EC, Hauer K, Becker C. Development of a common outcome data set for fall injury prevention trials: the prevention of falls network Europe consensus. J Am Geriatr Soc. 2005;53(9):1618-22.
29. Zarit SH, Reever KE, Bach-Peterson J. Relatives of the impaired elderly: Correlates of feelings of burden. Gerontologist. 1980;20(6):649-655.

30. Hebert R, Bravo G, Préville M. Reliability, validity and reference values of the Zarit burden interview for assessing informal caregivers of communitydwelling older persons with dementia. Can J Aging. 2000;19(4):494-507.

31. Wimo A, Gustavsson A, Jonsson L, Winblad B, Hsu MA, Gannon B. Application of resource utilization in dementia (RUD) instrument in a global setting. Alzheimer's Dement. 2013;9(4):429-435.e17.

32. OECD iLibrary | PPPs and exchange rates [Internet]. [cited 2020 Aug 17]. Available from: https://www.oecd-ilibrary.org/economics/data/aggregatenational-accounts/ppps-and-exchange-rates_data-00004-en.

33. Wübker A, Zwakhalen SMG, Challis D, Suhonen R, Karlsson S, Zabalegui A, et al. Costs of care for people with dementia just before and after nursing home placement: primary data from eight European countries. Eur I Health Econ. 2015;16(7):689-707.

34. Costa N, Wübker A, De Mauléon A, Zwakhalen SMG, Challis D, Leino-Kilpi H, et al. Costs of Care of Agitation Associated With Dementia in 8 European Countries: Results From the RightTimePlaceCare Study. J Am Med Dir Assoc. 2018;19(1):95.e1-95.e10

35. Farré M, Haro JM, Kostov B, Alvira C, Risco E, Miguel S, et al. Direct and indirect costs and resource use in dementia care: a cross-sectional study in patients living at home. Int J Nurs Stud. 2016;55:39-49.

36. Jönsson $L$, Jönhagen $M E$, Kilander $L$, Soininen $H$, Hallikainen $M$, Waldemar $G$, et al. Determinants of costs of care for patients with Alzheimer's disease. Int J Geriatr Psychiatry. 2006;21(5):449-59.

37. Organisation for Economic Co-operation and Development. OECD [Internet]. 2019 [cited 2019 Jul 9]. Available from: https://stats.oecd.org/ Index.aspx?DataSetCode=PPPGDP.

38. Agresti A. A survey of exact inference for contingency tables. Stat Sci. 1992; 7(1):131-53.

39. Feng Z, Coots LA, Kaganova Y, Wiener JM. Hospital and ED use among Medicare beneficiaries with dementia varies by setting and proximity to death. Health Aff. 2014;33(4):683-90.

40. Maust DT, Kales HC, McCammon RJ, Blow FC, Leggett A, Langa KM. Distress associated with dementia-related psychosis and agitation in relation to healthcare utilization and costs. Am J Geriatr Psychiatry. 2017;25(10):1074-82.

41. Cadigan RO, Grabowski DC, Givens JL, Mitchell SL. The quality of advanced dementia care in the nursing home: the role of special care units. Med Care. 2012;50(10):856-62.

42. Tyler DA, Feng Z, Leland NE, Gozalo P, Intrator O, Mor V. Trends in postacute care and staffing in US nursing homes, 2001-2010. J Am Med Dir Assoc. 2013;14(11):817-20

43. Sleeman KE, Perera G, Stewart R, Higginson IJ. Predictors of emergency department attendance by people with dementia in their last year of life: retrospective cohort study using linked clinical and administrative data. Alzheimers Dement. 2018:14(1):20-7.

44. Wirth R, Streicher M, Smoliner C, Kolb C, Hiesmayr M, Thiem U, et al. The impact of weight loss and low BMl on mortality of nursing home residents results from the nutritionDay in nursing homes. Clin Nutr. 2016;35(4):900-6.

45. Voisin T, Andrieu S, Cantet C, Vellas B. Predictive factors of hospitalizations in Alzheimer's disease: a two-year prospective study in 686 patients of the REAL.FR study. J Nutr Health Aging. 2010;14(4):288-91.

46. Sharma Y, Miller M, Kaambwa B, Shahi R, Hakendorf P, Horwood C, et al. Malnutrition and its association with readmission and death within 7 days and 8-180 days postdischarge in older patients: a prospective observational study. BMJ Open. 2017;7(11):e018443. https://doi.org/10.1136/bmjopen2017-018443.

47. Allan LM, Ballard CG, Rowan EN, Kenny RA. Incidence and prediction of falls in dementia: a prospective study in older people. PLoS One. 2009; 4(5):e5521.

48. Toot S, Devine M, Akporobaro A, Orrell M. Causes of Hospital Admission for People With Dementia: A Systematic Review and Meta-Analysis. J Am Med Dir Assoc. 2013;14:463-70.

49. Bynum JPW, Rabins PV, Weller W, Niefeld M, Anderson GF, Wu AW. The relationship between a dementia diagnosis, chronic illness, medicare expenditures, and hospital use. J Am Geriatr Soc. 2004;52(2):187-94.

50. Shafiee Hanjani L, Long D, Peel NM, Peeters G, Freeman CR, Hubbard RE. Interventions to Optimise Prescribing in Older People with Dementia: A Systematic Review. Drugs Aging. 2019:36:247-67 Springer International Publishing. 
51. Rankin A, Cadogan CA, Patterson SM, Kerse N, Cardwell CR, Bradley MC, Ryan C, Hughes C. Interventions to improve the appropriate use of polypharmacy for older people. Cochrane Database Syst Rev. 2018;(9). https://doi.org/10.1002/14651858.CD008165.pub4.

52. Booth V, Logan P, Harwood R, Hood V. Falls prevention interventions in older adults with cognitive impairment: a systematic review of reviews. Int $J$ Ther Rehabil. 2015;22(6):289-96.

53. Abdelhamid A, Bunn D, Copley M, Cowap V, Dickinson A, Gray L, et al. Effectiveness of interventions to directly support food and drink intake in people with dementia: systematic review and meta-analysis. BMC Geriatr. 2016;16(1):26.

54. Alldred D, Kennedy M, Hughes C, Chen T, Miller P. Interventions to optimise prescribing for older people in care homes ( review ). Cochrane Database Syst Rev. 2016;2:68.

55. Kröger E, Wilchesky M, Marcotte M, Voyer P, Morin M, Champoux N, et al. Medication Use Among Nursing Home Residents With Severe Dementia: Identifying Categories of Appropriateness and Elements of a Successful Intervention. J Am Med Dir Assoc. 2015;16:629 e1-17.

56. Giebel CM, Sutcliffe C, Renom-Guiteras A, Arve S, Hallberg IR, Soto M, et al. Depressive symptomatology in severe dementia in a European sample: prevalence, associated factors and prescription rate of antidepressants. Int Psychogeriatr. 2015;27(4):657-67.

57. Alzheimer Europe. Dementia in Europe Yearbook 2018. Comparison of National Dementia Strategies in Europe [Internet]; 2018. p. 1-56. Available from: https://www.alzheimer-europe.org/Policy/Country-comparisons/2018Comparsion-of-National-Dementia-Strategies.

58. Spasova S, Baeten R, Coster S, Ghailani D, Peña-Casas R, Bart V. Challenges in long-term care in Europe - A study of national policies 2018 -

Employment, Social Affairs \& Inclusion - European Commission [Internet] 2018. p. 1-66. Available from: https://ec.europa.eu/social/main.jsp?catld= 89\&furtherNews=yes\&newsld=9185\&langld=en.

\section{Publisher's Note}

Springer Nature remains neutral with regard to jurisdictional claims in published maps and institutional affiliations.

Ready to submit your research? Choose BMC and benefit from:

- fast, convenient online submission

- thorough peer review by experienced researchers in your field

- rapid publication on acceptance

- support for research data, including large and complex data types

- gold Open Access which fosters wider collaboration and increased citations

- maximum visibility for your research: over $100 \mathrm{M}$ website views per year

At $\mathrm{BMC}$, research is always in progress.

Learn more biomedcentral.com/submissions 